\title{
Nonlinear structural behaviour of membrane-type LNG carrier cargo containment systems under impact pressure loads at $-163^{\circ} \mathrm{C}$
}

\author{
J.M. Sohn"a, D.M. Bae ${ }^{a}$, S.Y. Bae and J.K. Paik ${ }^{\mathrm{b}, \mathrm{c}^{*}}$ \\ ${ }^{a}$ Department of Naval Architecture and Marine Systems Engineering, Pukyong National \\ University, Busan 48513, Korea ${ }^{b}$ Department of Naval Architecture and Ocean Engineering, \\ Pusan National University, Busan 46241, Korea; ${ }^{c}$ Department of Mechanical Engineering, \\ University College London, London WC1E 7JE, UK
}

This paper is a sequel to the paper dealing with quasi-static responses previously studied by the authors. The structural failure of membrane-type liquefied natural gas carrier (LNGC) cargo tank is an important issue in the construction of ultra-large an LNG carrier. However, quasi-static analysis to investigate the structural failure is difficult and tends to give conservative results. To compensate the weak points of the quasi-static analysis, a procedure for the dynamic analysis was developed to assess the structural failure using nonlinear finite element method.

A nonlinear finite element method is employed to model metal membrane, insulation and surface contacts. Various element formulations are tested at different points along a corrugated surface to optimise the accuracy of the model with respect to computation time. Material properties used in the model are calibrated based on experimentally measured values at cryogenic conditions $\left(-163^{\circ} \mathrm{C}\right)$. The model is used to predict the structural failure under different impact pressure loads and loading patterns. It is concluded that the structural damage is less likely to occur under 30 bar.

Keywords: liquefied natural gas carrier (LNGC); membrane-type LNGC cargo containment system; dynamic structural analysis; sloshing impact; finite element method

\section{Introduction}

The liquefied natural gas (LNG) shipping market driven by growth in global liquefaction capacity and nuclear-phobic policies has evolved over the last decade. In recent years, the 
average size of an LNG carrier (LNGC) has been increased to maximise transport efficiency. One concern about the LNG tanks is that large sloshing impact pressure can cause structural failure resulting in liquid leaking through the primary barrier into the membrane space. When LNG leaks into the primary barrier, the pressure in the primary insulation will built up the temperature of steel in the inner hull will drop. Thus, understanding the structural behaviour of the LNGC cargo containment system is important to minimize risk. An LNGC cargo containment system is composed of a primary barrier, plywood and reinforced polyurethane foam (RPUF). This distinctive structure has been the focus of many studies on the structural integrity of membrane-type cargo systems. Some other studies focused on the structural responses of LNGC insulation system (Lee and Kim 2006, Chun et al. 2009). The present study evaluates the structural behaviour of the primary barrier, which is in direct contact with LNG. It also examines structural failure, which is a challenging issue in the design of LNGC cargo containment systems.

There are three levels of strength assessment for LNG containment systems: static stress finite element (FE) analysis, dynamic FE analysis and dynamic FE analysis accounting for fluidstructure interaction (FSI) (ABS 2009). Static stress analysis is used to determine principal features such as maximum stress and excessive deformation (Wang et al. 2008, Paik et al. 2011). Transient FE analysis is used to understand dynamic characteristics using the pressure-time history obtained from computational fluid dynamics (CFD) or sloshing model tests. FSI analysis is used to model the sloshing effect by considering both fluid flow and structural deformation (Lee et al. 2004, 2013, 2015). ABS guidelines (2009) state that dynamic analysis should be preferentially conducted; FSI analysis is required if systems do not pass dynamic analysis. 
In the present study, nonlinear structural responses are assessed for various values of an impact magnitude for dynamic analysis. Numerical techniques are introduced for evaluating the nonlinear structural behaviour of membrane-type LNGC systems by considering the failure strain under cryogenic conditions. Sloshing loads are described using the triangular impact pressure in the time domain, and three types of loading patterns are used to consider the load direction based on the filling level of LNG. The present observations suggest that the proposed methodology will be applicable to FSI analysis.

\section{Modelling techniques}

This study follows the framework of Paik's FE model, which considers a corrugated structure, insulation system and mastic (Paik et al. 2011). For dynamic analysis, an explicit code is appropriate for solving structural problems related to short duration events with severe loadings. Implicit analysis requires a numerical solver to invert the stiffness matrix several times over the time step. This matrix inversion is an expensive operation, especially for large models. However, explicit code does not require this step. This study uses an explicit code to solve the dynamic solution to include treatment of contact and material nonlinearities and achieve a desired accuracy with less computation time. The following sections describe methods used to apply explicit computations to LNGC containment systems.

\subsection{LNGC containment system}

A membrane-type LNGC cargo tank system is a cryogenic liner composed of a primary metallic membrane positioned on top of a prefabricated insulation panel, which includes a complete secondary membrane, as shown in Figure 1. The primary membrane is folded to create 
corrugations; it is made of stainless steel $304 \mathrm{~L}$ and is $1.2 \mathrm{~mm}$ thick. The primary membrane directly contains LNG cargo and is fixed to an insulation system. The insulation system consists of a load-bearing system made from prefabricated panels of RPUF; this load-bearing system is used in the primary and secondary insulation layers as well as the secondary membrane. The total insulation thickness is $270 \mathrm{~mm}$. Insulation panels are bonded to the inner hull using resin ropes, which serve a double purpose: anchoring the insulation and evenly distributing the load (GTT 2016).

Figure 1. (a) Mark III stainless steel corrugated membrane and (b) Mark III prefabricated panel (GTT 2016).

\subsection{Finite element modelling}

FE modelling is used to transform a physical system into a mathematical model. Isoperimetric quadrilateral elements are used to represent the 1.2-mm-thick plate and knot, which is the intersection of small and large corrugations; each modelled element comprises four nodes with six degrees of freedom per node. The insulation system is idealised as a cuboid and modelled using quadratic, 8-node, solid elements with nodal rotation.

The location of high stress moves as stress waves propagate through the mesh. FE models with a fine mesh capture this complexity and yield more accurate results with an increase in the computation time. The mesh size must be optimised to balance accuracy with the computation time. Similar to our previous study, a fine mesh is applied only to the corrugated plate to achieve accurate FEA results. Compared with corrugated plate elements, the insulation system uses a coarse mesh that is five times larger; this reduces the computation time. The FE analysis generates 40,000 four-node shell elements and 120,000 eight-node solid elements (Paik et al., 
2011).

Insulation is modelled as a single system that shares nodes on plywood, triplex and RPUF. A corrugated plate model is simply positioned on top of a prefabricated insulation panel. However, the mesh density significantly varies between the plate and insulation; thus, contact elements are needed. Single-surface contact algorithm is used for the corrugated plate; all external surfaces in the model are searched to determine if penetration has occurred. Interaction contact is detected between the corrugated plate and insulation when a contacting node penetrates the target surface. The insulation system is selected as the target body because it comprises a coarse mesh, and the corrugated plate is selected as the contact body because it comprises a relatively finer mesh (ANSYS/LS-DYNA 2015).

To ensure a stable and accurate solution, the time step used in the explicit code is limited by the Courant-Friedrichs-Lewy (CFL) condition (Courant et al. 1967). The time step in the explicit code is limited such that a stress wave cannot travel further than the smallest characteristic element dimension in a mesh during a single time step. The minimum value of $h / c$ for all elements in the model is used to calculate the time step. $h$ is the characteristic dimension of an element, the area of the element divided by its maximum edge; $c$ is the speed of sound in the local material of an element. For a mesh with a characteristic dimension of $1 \mathrm{~mm}$ and stainless steel elements in which the speed of sound is $5790 \mathrm{~m} / \mathrm{s}$, the resulting stability time step would be approximately $0.17 \mu$ s. This value implies that the number of time steps required to solve the simulation is dictated by the smallest element in the model. 


\subsection{Element formulation}

Saving CPU time is a primary concern when performing a series of computations. Reduced-node integration elements save CPU time by minimising element processing. Single-point integration elements are robust for modelling large deformations; however, they are susceptible to spurious, zero-energy deformation modes. These so-called hourglass modes are nonphysical deformation modes that occur in undisintegrated elements and produce no stress. The accuracy of stress calculations is directly related to the number of integration points. There are two methods that can be used to solve the hourglass problem. An hourglass-control algorithm can be used whenever one-point integration is necessary. Alternately, integrated elements may be used, which are computationally costly.

This section investigates the effects of element formulations on the structural behaviour of the model to optimise time efficiency and accuracy of results. Two reduced-integration elements $(\mathrm{ELFORM}=1$ and 2$)$ and $2 \times 2$ integrated elements $(\mathrm{ELFORM}=6$ and 16) are considered for the corrugated panel. ELFORM 2 and 16 are based on the Reissner-Mindlin kinematic assumption, which includes mid-surface displacements plus rotations to describe shear deformation. ELFORM 1 and 6 are based on the formulation of degenerated continuum elements. Deformations in the $z$ direction due to the application of 10 bar pressure are summarised in Table 1 for these four shell element formulations. Several monitoring points were selected on a corrugated metal surface, as shown in Figure 2. Deformations listed in Table 1 are similar for all shell element formulations tested. The gap is only approximately 5\%, integrated elements are 1.5-3 times more expensive than reduced elements. Moreover, the hourglass energy is much less than the internal energy in reduced elements. Therefore, Belytschko-Tsay elements (ELFORM = 
2) are used to improve time efficiency.

Figure 2. Measurement (monitoring) points of the corrugated membrane.

Table 1. Comparison of displacements and simulation times for different shell element formulations.

The deformation magnitude depends on a monitoring point; from greatest to smallest deformation, the order of monitoring points is as follows: (E) the middle of the large corrugation, (D) the middle of the small corrugation, (B) the knot, (A) the vertex of the small corrugation and (C) the vertex of the large corrugation. Point $\mathrm{E}$ has the largest curvature and exhibits the largest deformation. Point $\mathrm{C}$ exhibits the smallest deformation because the vertex can only move upward. Points $\mathrm{G}$ and $\mathrm{F}$ have the same displacement as points $\mathrm{D}$ and $\mathrm{E}$ because of their symmetric geometry.

\subsection{Material properties}

Paik et al. (2011) performed tensile coupon tests to obtain the engineering stress-engineering strain relation for stainless steel STS304 at $22^{\circ} \mathrm{C}$ and $-163^{\circ} \mathrm{C}$. DNV (2006) summarized the material stiffness properties of plywood laminate, plywood plates and RPUF at room temperature and cryogenic conditions. Arswendy and Moan (2015) observed the crushing and buckling failures of plywood components.

Structural behaviour is directly affected by material properties, especially by yield stress and 
failure strain. These two properties are closely related to the effects of strain rate on the sloshing impact load. Cowper and Symonds (1957) proposed the following equations to relate strain-rate sensitivity to the dynamic yield strength and dynamic failure strain.

$$
\begin{gathered}
\frac{\sigma_{Y d}}{\sigma_{Y}}=1.0+\left(\frac{\dot{\varepsilon}}{C}\right)^{1 / q}, \\
\frac{\varepsilon_{f c d}}{\varepsilon_{f c}}=\left[1+\left(\frac{\dot{\varepsilon}}{C}\right)^{1 / q}\right]^{-1},
\end{gathered}
$$

Where, $C$ and $q$ are experimentally determined coefficients (see Table 2). The dynamic yield strength (normalised by the static yield strength) versus strain rate is shown in Figure 3 for the 304 stainless steel, mild steel and high-tensile steel. The material yield strength increases with an increase in the strain rate. It is evident that coefficients $C$ and $q$ depend on the material type, among other factors. The rate of increase of $\sigma_{Y d} / \sigma_{Y}$ is the steepest for mild steel.

Table 2. Coefficients of the Cowper-Symonds constitutive equation for different steel types.

Figure 3. Plot of the dynamic yield strength (normalised by the static yield strength) versus strain rate for 304 stainless steel, mild steel and high-tensile steel.

ANSYS/LS-DYNA (2015) provides a Cowper-Symonds strain-rate model (1957) that scales the yield stress with the factor; $C$ and $q$ are easily determined for different materials. Failure strain is defined as the tensile strain at which failure begins. Hughes and Paik (2010) reported that the critical failure strain $\varepsilon_{f c}$ should be expressed as a function of the element size and plate 
thickness in an FE analysis:

$$
\frac{\varepsilon_{f c}}{\varepsilon_{f}}=\gamma d_{1}\left(\frac{t}{s}\right)^{d_{2}}
$$

Where, $t$ is the thickness of the element, $s$ is the length of the element, $d_{1}$ and $d_{2}$ are the test constants, $\varepsilon_{f}$ is the material failure strain obtained from tensile coupon tests under quasi-static loading conditions and $\gamma$ is the adjustment factor associated with local strains due to bending or folding effects. For very thin walls, $\gamma=1.0$.

A numerical tensile test was conducted using ANSYS/LS-DYNA code (2015) to define the failure strain $\varepsilon_{f c}$ of steel at $-163^{\circ} \mathrm{C}$. The failure strain used for $\mathrm{FE}$ was carefully selected to ensure that resulting FE computations matched the experimental material behaviour determined from tensile tests (Paik et al. 2011). Figure 4 shows the FE model and an experimental sample immediately after fracturing under an axial tensile load. A trial-and-error technique was applied to search for the failure strain to be used for FEA to ensure the equality of computational and experimental results; the trial-and-error analyses of the ANSYS/LS-DYNA code (2015) are shown in Figure 5. The corrugated membrane was $1.2 \mathrm{~mm}$ thick, mesh size was $1 \mathrm{~mm}$ and critical failure (engineering) strain of the material was determined as $\varepsilon_{f c}=1.726 \varepsilon_{f}$ with $d_{1}=1.667$, $d_{2}=0.197$ and $\gamma=1.0$.

Figure 4. (a) A tensile coupon test specimen, (b) its FEM prediction.

Figure 5. Comparison of the engineering stress-engineering strain relation between the test and explicit LS-DYNA simulation with a mesh size of $1 \mathrm{~mm}$ at $-163^{\circ} \mathrm{C}$. 
The relation between the failure strain used for FEA and the mesh size is shown in Figure 6 for several steel types. The FEA failure strain tends to decrease as the mesh size increases, approaching the experimental value of the failure strain. On the basis of these findings, the true stress-true strain relation of the material was adjusted by expanding the value of the failure strain, as shown in Figure 7.

Figure 6. Critical failure strain used for the LS-DYNA FE simulation as a function of mesh size under quasi-static loading conditions.

Figure 7. True stress-true strain curve with an extended failure strain and a mesh size of $1 \mathrm{~mm}$.

\section{Sloshing impact load}

Model tests and CFD simulations (Lee et al. 2004, Kuo et al. 2009, Brizzolara 2011, Kim et al. 2015) have revealed significant variation in sloshing loads. This has been shown in. Lee et al. (2004) specifies that the filling level affected the peak value of pressure for tank No.2 in a $138 \mathrm{k}$ LNGC; a 30\% filling level induced a pressure of up to 30 bar. ABS guidelines (2009) summarise the general pattern of sloshing impact loads from model tests. They state that most of the sloshing impact load has a symmetric loading pattern, or that skewness closes to 1.0. The skewness parameter $S$ is introduced to define the pattern of a triangular impulse:

$$
S=(2 \times \text { risetime }) /(\text { duration }) \text {. }
$$

An isosceles triangle is used to represent the sloshing impact load, as shown in Figure 8 . It is drawn such that $20 \%$ of the peak pressure remains after $90 \%$ of the duration; this accounts for the steady-state static pressure of cargo. 
Figure 8. Idealised time history of the sloshing impact pressure.

It is not easy to directly apply sloshing load in CFD and model test to structural analysis owing to diversity and uncertainties. Nevertheless, sloshing loads exhibit a general trend that large pressures are correlated with short rise times, down to $<1.0 \mathrm{~ms}$. Also, a significant portion of the peak pressure is under 10 bar. Based on the general trend, this study set the peak pressure from 5-30 bar. The loading direction, which is related to the filling level, is also considered, as shown in Figure 9. In the present study, three angles of attack were considered, i.e. $\theta=90^{\circ}, 45^{\circ}$ and $0^{\circ}$. The last two cases, i.e. $\theta=45^{\circ}$ and $0^{\circ}$, were considered with respect to both large and small corrugations.

Figure 9. Angles of attack of sloshing impacts.

However, depending on the magnitude of the load, the duration time is beyond classification; therefore, the duration time is excluded from the variables. Eigenvalue analysis is performed so that the duration time is involved in the dynamic region. This is because the structural behaviour does not depend on the duration in a quasi-static region, and there is a rapid change in an impulse region. The natural period of a membrane-type LNGC cargo containment system is approximately $1.4 \mathrm{~ms}$. This value is similar to the natural frequency of a Mark III cargo containment system, $1.0-2.0 \mathrm{~ms}$. Finally, the duration time $\tau=3 \mathrm{~ms}$ provides the maximum response, except in the case when resonance was selected. 


\section{Results and Discussion}

Structural damage to a primary barrier must be avoided. In the present study, structural damage is defined as the effective plastic strain exceeds of 0.623 failure strain. The termination time for structural analysis is set as $100 \mathrm{~ms}$ to capture the structural failure of membrane-type LNGC cargo tanks, i.e. the analysis continues after sloshing load is unloaded. Figures 10 shows the peak pressure versus time until first failure. First failure occurs around the knot and folded structure. However, this damage is caused by the accumulation of strain energy due to effect of continuance time regardless of sloshing loads. The structural failure of membrane-type LNGC cargo tanks is undetected until peak pressures up to 30 bar at the duration time $\tau=3 \mathrm{~ms}$. However, large sloshing loads are correlated with short rise times, it can be concluded that the probability of structural failure is very low.

Figure 10. Peak pressure against the time until first failure occurs.

Furthermore, the yield limit of the primary membrane are evaluated to determine the structural strength of a containment system. Dynamic FE analysis on the containment system is performed to obtain the stress-strain field. The stress must satisfy the following condition:

$$
\sigma_{\max }^{e q} \leq \sigma_{c}
$$

Where, $\sigma_{c}$ is the permissible normal stress defined as the multiple of the ultimate strength $\left(\sigma_{Y}\right)$ of a material and the strength reduction factor. The ultimate strength of STS304 is $1192 \mathrm{MPa}$ at $-163^{\circ} \mathrm{C}$ (Paik et al. 2011), and the strength reduction factor are 0.8-1.0 for ultimate strength (ABS 2009); 0.8 is a more conservative estimate. The von Mises stresses are summarised in 
Table 3 for different loading patterns. Shaded cells indicated that the calculated value of the stress exceeds the criterion for ultimate strength. It appears that a membrane-type LNGC cargo tank exhibits sufficient structural strength under a peak pressure of 10 bar regardless of the loading pattern.

Notably, there are specific loading patterns that do not satisfy the maximum-stress criterion, although the probability is low. In particular, both large and small corrugations are dented when the impact sloshing load is horizontally and diagonally applied, as shown in Figure 11. Maximum stress is concentrated on the knot and folded structure, which deform less than the corrugations. The peak pressure is 30 bar when the angle of attack is $45^{\circ}$ in the $-x$ direction; this exceeds the yield stress, but failure does not occur because of modified of the stress-strain curve in FE analysis.

Table 3. Summary of von Mises stresses for different loading patterns.

Figure 11. von Mises stress distributions for impact pressures applied in $x$ and $y$ directions.

Dynamic FE analysis is performed to obtain the maximum deformation fields in the containment system. The following condition must be satisfied (Paik and Shin, 2006):

$$
w_{\max } \leq w_{c}
$$

Where, $w_{c}$ is the permissible deformation of each component in metres. This is the value recommended by the manufacturer of the LNGC containment system; $w_{\mathrm{c}}$ is sometimes 
normalised by $1 / 1000^{\text {th }}$ of a tank length. Two types of deformations were observed as shown in the Figure 12. One is the maximum value in the duration time and another is the permanent set after release of the loading. These are similar in tendency and the maximum gap is within $4 \mathrm{~mm}$.

Figure 12. Comparisons between maximum and permanent deflection.

The maximum deformation of the primary barrier for a membrane-type LNGC containment system is investigated by varying the loading pattern and observing several monitoring points, as shown in Figures 13-17. Deformation increases as the applied pressure increases. Small deformations tend to linearly respond to pressure, while large deformation makes dramatically change starting from $15 \mathrm{bar}$.

For example, for a $217 \mathrm{k}$ LNGC containment system, the length of tank No.2 is $41 \mathrm{~m}$, and $w_{c}$ is defined as $40 \mathrm{~mm}$. The allowable peak pressure is approximately $15.33 \mathrm{bar}$. This peak pressure is more than 6-7 times the maximum cargo pressure load of today's very large membrane-type LNGCs. Also, this value is $12 \%$ less than static structural strength, it is reasonable when considering the amplitude of the dynamic load.

Figure 13 Peak pressure versus deformation of the corrugation at the angle of $\theta=90^{\circ}$ of sloshing pressure.

Figure 14. Peak pressure versus deformation of large corrugation; $\theta=45^{\circ}$ in the $-x$ direction.

Figure 15. Peak pressure versus deformation of the small corrugation at the angle of attack; $\theta=$ $45^{\circ}$ in the $-y$ direction. 
Figure 16. Peak pressure versus deformation of large corrugation at the angle of attack; $\theta=0^{\circ}$ in the $-x$ direction.

Figure 17. Peak pressure versus deformation of the small corrugation at the angle of attack; with $\theta=0^{\circ}$ in the $-y$ direction.

Diagonally sloshing loads applied to large corrugations caused the largest deformations. Deflection is the smallest when the impact pressure is applied in the $-z$ direction; it exhibits a linear structural response. This suggests that the structural behaviour may be overestimated when only the vertical loading on an LNGC cargo tank is considered.

The point at which the maximum deflection was varied depends on the loading direction. Regions of curvature on the corrugation are much less resistant to deflection than the vertex of the corrugation. In addition, the loading surface seems to deflect more. The loading surface is likely to endure greater tensile stress due to unfolding, while the opposite surface is under compressive stress due to bending. Even if a large deformation occurs at the loading surface, the opposite surface is more likely to lose structural strength due to buckling.

The effect of the angle of attack on the deformation of the corrugation is shown in Figures 18 and 19 for sloshing impacts applied to the large and small corrugations, respectively. The maximum deformation occurs at Point E when the sloshing impacts are applied to the large corrugation and at Point $\mathrm{F}$ when the sloshing impacts are applied to the small corrugation. The angle of attack $\theta=45^{\circ}$ causes the largest deformation in the corrugation. Also, the angle of attack has a large impact on the deformation as the sloshing load increases. 
Figure 18. Effect of the angle of attack on the deformation of the corrugation at monitoring point E for impact pressure applied in the $-x$ direction.

Figure 19. Effect of the angle of attack on the deformation of the corrugation at monitoring point F for impact pressure applied in the $-y$ direction.

\section{Concluding remarks}

The objective of the present paper was to investigate the structural behaviour of a membrane (Mark III)-type LNGC cargo containment system under sloshing impact pressure using nonlinear FEM. The FE structural modelling techniques were investigated in terms of selection of element, shell element formulation and technique for considering material properties. Based on numerical analysis, the elastic-plastic deflection characteristics of the corrugated membrane were examined. The following conclusions were drawn:

- Belytschko-Tsay shell element formulations are robust to large deformations and prevent zero-energy modes by using fine mesh size. These elements were selected to investigate the structural behaviour of the primary barrier in an LNG cargo container.

- The critical failure strain should be adjusted by considering the element size and plate thickness for FE analysis. As the mesh size increases, the FE failure strain decreases approaching the failure strain obtained experimentally from tensile tests.

- The primary barrier of LNGs cargo containers has sufficient structural integrity at 15 bar under sloshing impact loads. Structural damage, defined as exceeding the failure strain, is less likely to occur under 30bar.

- The largest deflection occurs for diagonally applied loads, followed by horizontal and 
vertical loads. It is important to consider the loading directions when investigating the nonlinear structural response under sloshing impact loads. A primary barrier with curvature that is not active in load-bearing can lose structural strength due to buckling.

- The nonlinear FEM technique developed in this study can be applied to predict the relation between sloshing impact pressure and corrugation deformation.

The insights developed in the present study will be very useful in the structural design of corrugated membranes subject to sloshing impact pressure. Further studies are expected to identify the design loads for sloshing impact using the probabilistic approach. Also, the sloshing loading scenarios should be set by accounting for the tank filling level, rolling angle and the duration and amplitude of tank motion.

\section{Acknowledgements}

This work was supported by the Pukyong National University Research Fund in 2015 (20151258).

\section{REFERENCES}

ABS. 2009. Guidance notes on strength assessment of membrane-type LNG containment systems under sloshing loads. Houston (TX): American Bureau of Shipping.

ANSYS LS-DYNA. 2015. Version 16.1. Canonsburg (PA): ANSYS.

Arswendy A and Moan T. 2015. Strength and stiffness assessment of an LNG containment system - crushing and buckling failure analysis of plywood components. Engineering Failure Analysis. Published online.

Brizzolara S, Savio L, Viviani M, Chen Y, Temarel P, Couty N, Hoflack S, Diebold L, Moirod N and Iglesias AS. 2011. Comparison of experimental and numerical sloshing loads in partially filled tanks. Ships and Offshore Structure 6(1-2):15-43. 
Chun MS, Kim MH, Kim WS, Kim SH and Lee JM. 2009. Experimental investigation on the impact behavior of membrane type LNG carrier insulation system. Journal of Loss Prevention in the Process Industries 22:901907.

Courant R, Friedrichs K and Lewy H. 1967. On the partial difference equations of mathematical physics. New York (NY): IBM Journal.

Cowper GR and Symonds PS. 1957. Strain-hardening and strain-rate effects in the impact loading of cantilever beams. Technical Report No. 28. Division of Applied Mathematics. Providence (RI): Brown University.

DNV. 2006. Classification Notes No.30.9: Sloshing analysis of LNG membrane tanks. Oslo (Norway): Det Norke Veritas.

Forrestal MJ and Sagartz MJ. 1978. Elastic-plastic response of 304 stainless steel beams to impulse loads. Journal of Applied Mechanics 45: 685-687.

Gaztransport \& Technigaz. 2016. Saint-Rémy-lès-Chevreuse (France): http://www.gtt.fr/en/technologiesservices/our-technologies/mark-iii.

Hsu SS and Jones N. 2004. Dynamic Axial Crushing of Aluminum Alloy 6063-T6 Circular Tubes. Latin American Journal of Solids and Structures 1(3): 277-296.

Hughes OF and Paik JK. 2010. Ship structural analysis and design. Jersey City (NJ): The Society of Naval Architects and Marine Engineers.

Kim SY, Kim KY and Kim Y. 2015. Comparative study on pressure sensors for sloshing experiment. Ocean Engineering 94:199-212.

Kuo JF, Campbell B, Ding Z, Hoie SM, Rinehar, AJ, Sandstrom, RE and Yung TW. 2009. LNG tank sloshing assessment methodology-The new generation. International Journal of Offshore and Polar Engineers 19(4): 241-253.

Langdon GK and Schleyer GS. 2005. Inelastic deformation and failure of $1 / 4$ scale profiled stainless steel blast wall panels. Part II: analytical modelling considerations. International Journal of Impact Engineering 31(4): 371 399.

Lee H, Kim JW and Hwang C. 2004. Dynamic strength analysis for membrane type LNG containment system due to sloshing impact load. ABS Technical papers. Houston (TX): American Bureau of Shipping. 
Lee CS, Cho JR, Kim WS, Noh BJ, Kim MH and Lee JM. 2013. Evaluation of sloshing resistance performance for LNG carrier, International Journal of Naval Architecture Ocean Engineering 5:11-20.

Lee JM and Kim MH. 2006. Impact strength assessment of LNG carrier insulation system. Trans. Pfaffikon (Switzerland): Tech Publications.

Lee SE, Kim BJ, Seo JK, Ha YC, Matsumoto T, Byeon SH and Paik JK. 2015. Nonlinear impact response analysis of LNG FPSO cargo tank structures under sloshing loads. Ships and Offshore Structures. Published online.

Paik JK. 2007. Practical techniques for finite element modelling to simulate structural crashworthiness in ship collision and grounding (Part I: Theory). Ships and Offshore Structures 2(1): 69-80.

Paik JK and Chung JY. 1999. On dynamic / impact tensile strength characteristics of thin high tensile steel materials for automobiles. Transactions of the Korea Society of Automotive Engineers 7(2):268-278.

Paik JK and Kim TH. 2009. Safety case study of MARK III type LNG carrier cargo containment systems under dropped object impacts. Department of Naval Architecture and Ocean Engineering. Busan (Korea): Pusan National University.

Paik JK, Lee JM, Shin YS, Wang G. 2004. Design principles and criteria for ship structures under impact pressure loads arising from sloshing, slamming and green sea. SNAME Transactions 112:292-313.

Paik JK and Shin YS. 2006. Structural damage and strength criteria for ship stiffened panels under impact pressure actions arising from sloshing, slamming and green water. Ships and Offshore Structures 1(3):249-256.

Paik JK, Sohn JM, Shin YS, Thayamballi AK and Suh YS. 2011. Nonlinear structural analysis of membrane-type LNG carrier cargo containment system under cargo static pressure loads at the cryogenic condition with a temperature of $-163^{\circ} \mathrm{C}$. Ships and Offshore Structures 6(4): 311-322.

Paik JK and Thayamballi AK. 2007. Ship-shaped offshore installations: design, building, and operation, Cambridge (England): Cambridge University Press.

Wang B, Yu H, Basu R, Lee H, Kwon JC, Jeon BY, Kim JH, Daley and Kendrick A. 2008. Structural response of cargo containment systems in LNG carriers under ice loads. International Conference and Exhibition on Performance of Ships and Structures in Ice. Banff (Canada): July 20-23. 


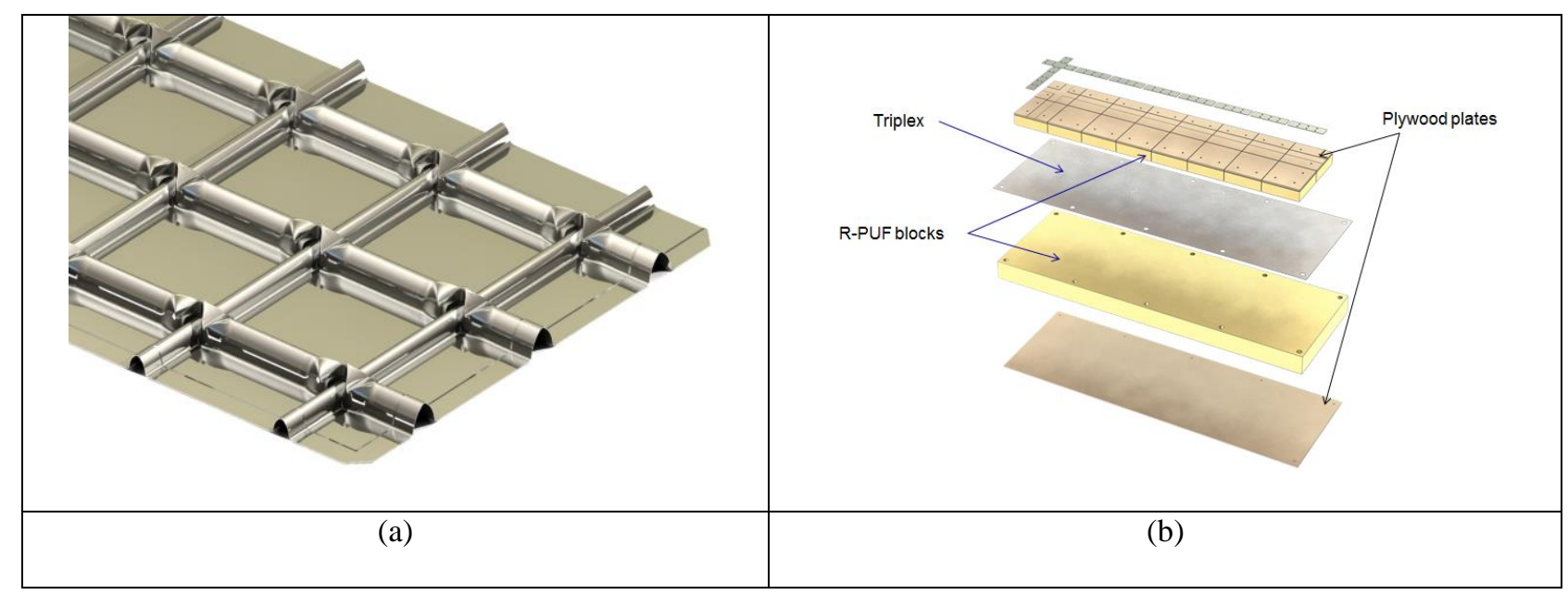

Figure 1. (a) Mark III stainless steel corrugated membrane and (b) Mark III prefabricated panel (GTT 2016).

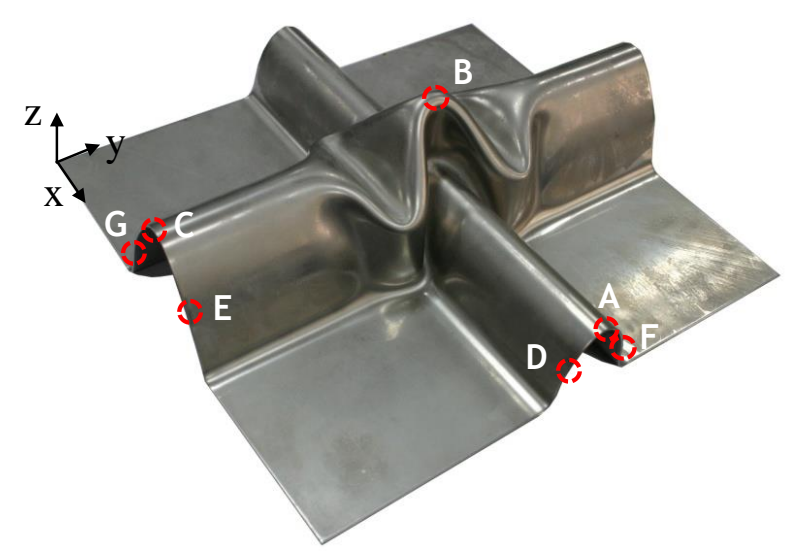

Figure 2. Measurement (monitoring) points of the corrugated membrane.

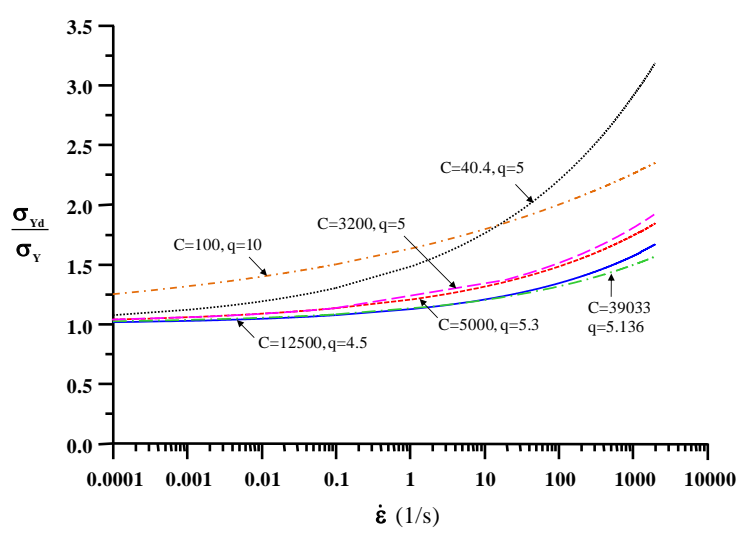


Figure 3. Plot of the dynamic yield strength (normalised by the static yield strength) versus strain rate for 304 stainless steel, mild steel and high-tensile steel.

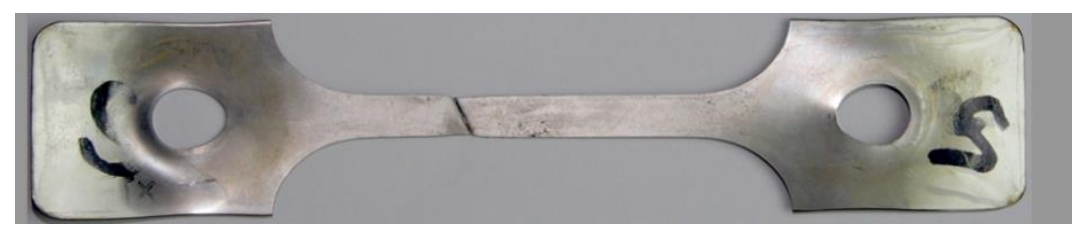

(a)

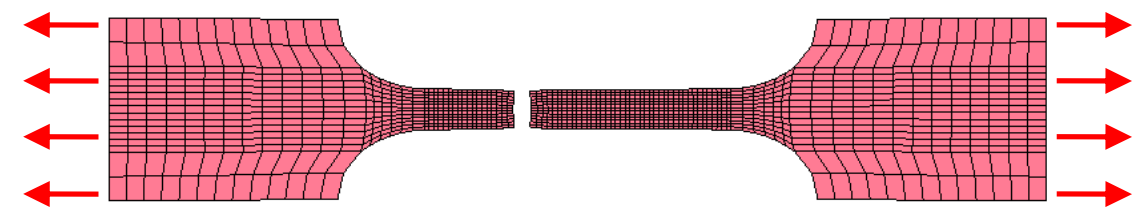

(b)

Figure 4. (a) A tensile coupon test specimen, (b) its FEM prediction.

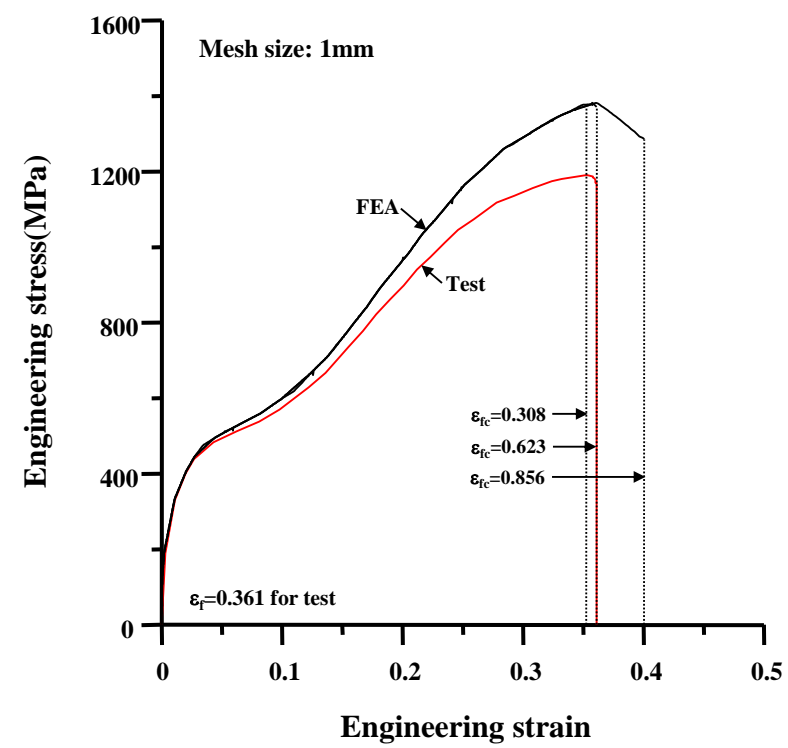

Figure 5. Comparison of the engineering stress-engineering strain relation between the test and explicit LS-DYNA simulation with a mesh size of $1 \mathrm{~mm}$ at $-163^{\circ} \mathrm{C}$. 


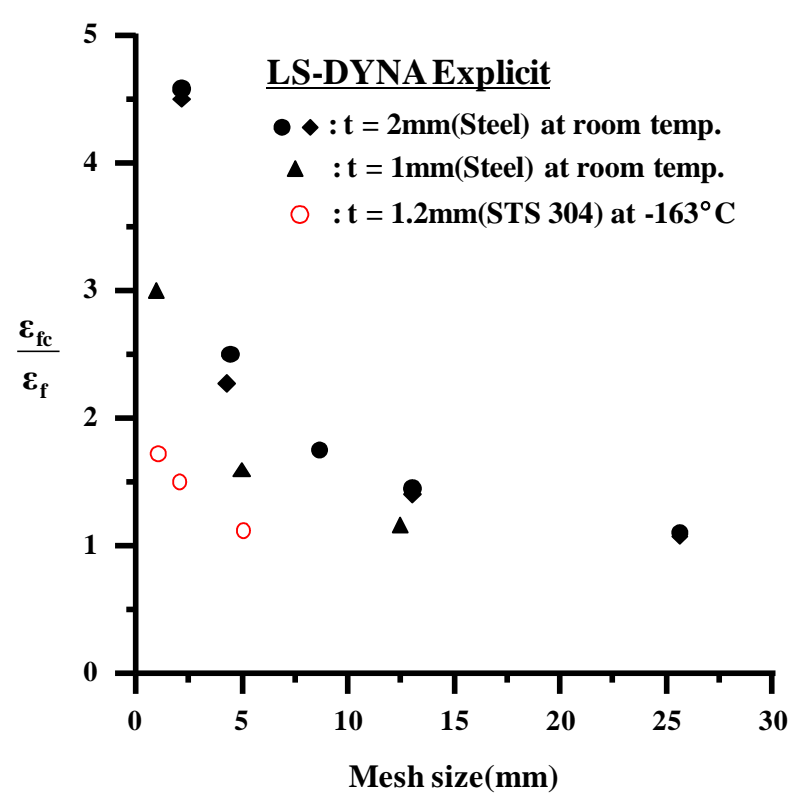

Figure 6. Critical failure strain used for the LS-DYNA FE simulation as a function of mesh size under quasi-static loading conditions.

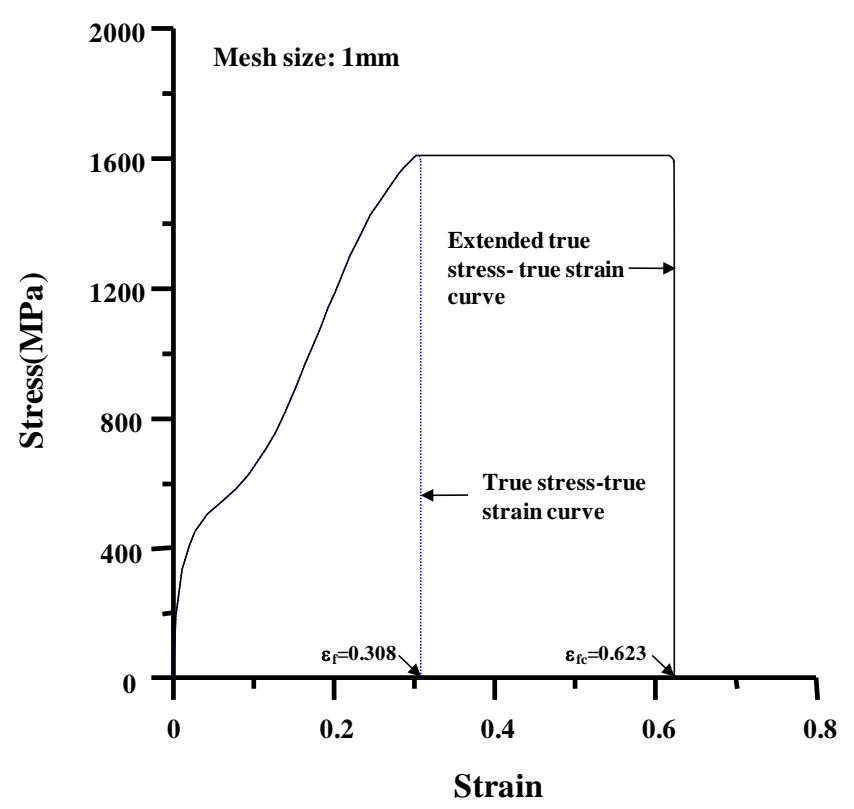

Figure 7. True stress-true strain curve with an extended failure strain and a mesh size of $1 \mathrm{~mm}$. 


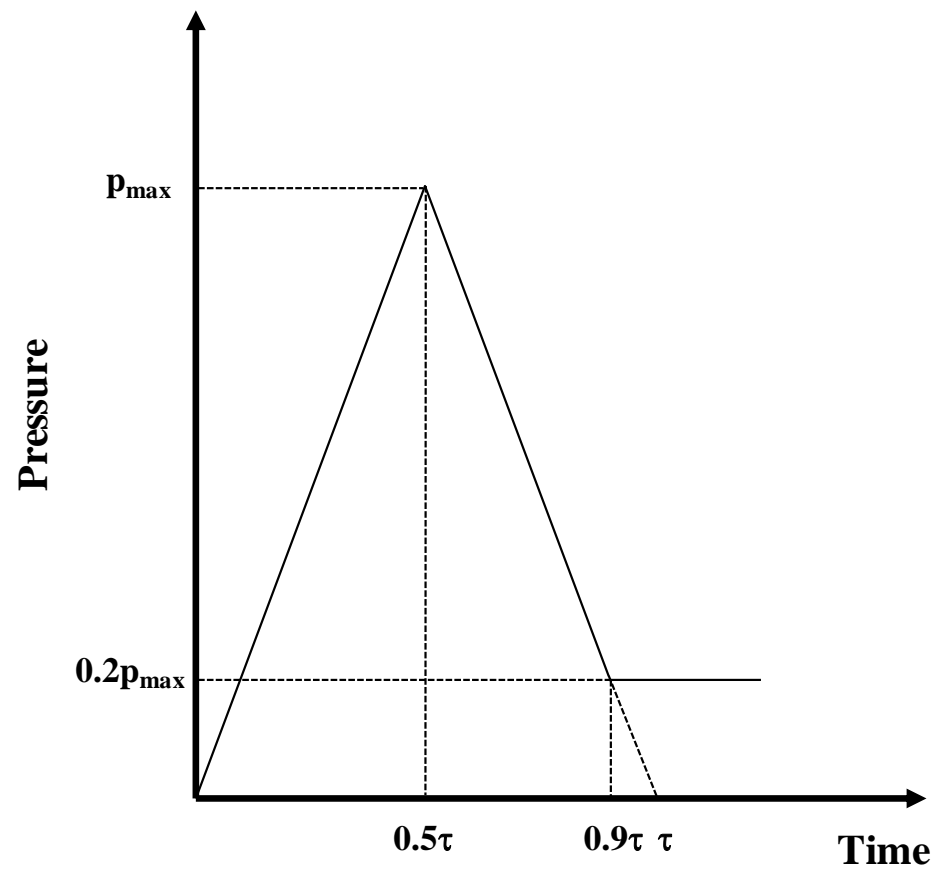

Figure 8. Idealised time history of the sloshing impact pressure.

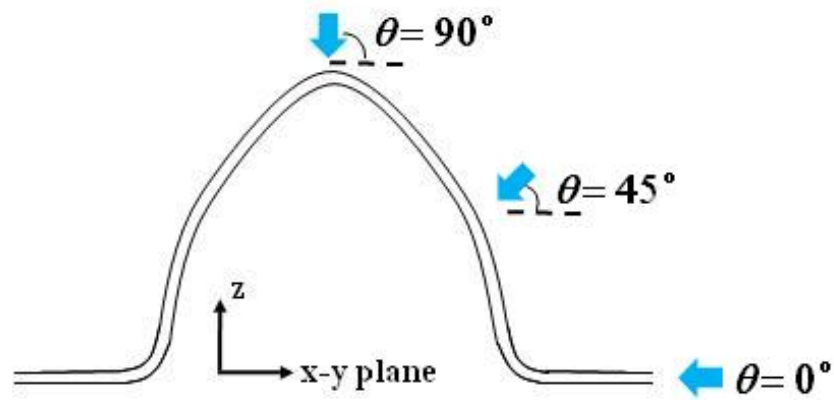

Figure 9. Angles of attack of sloshing impacts. 


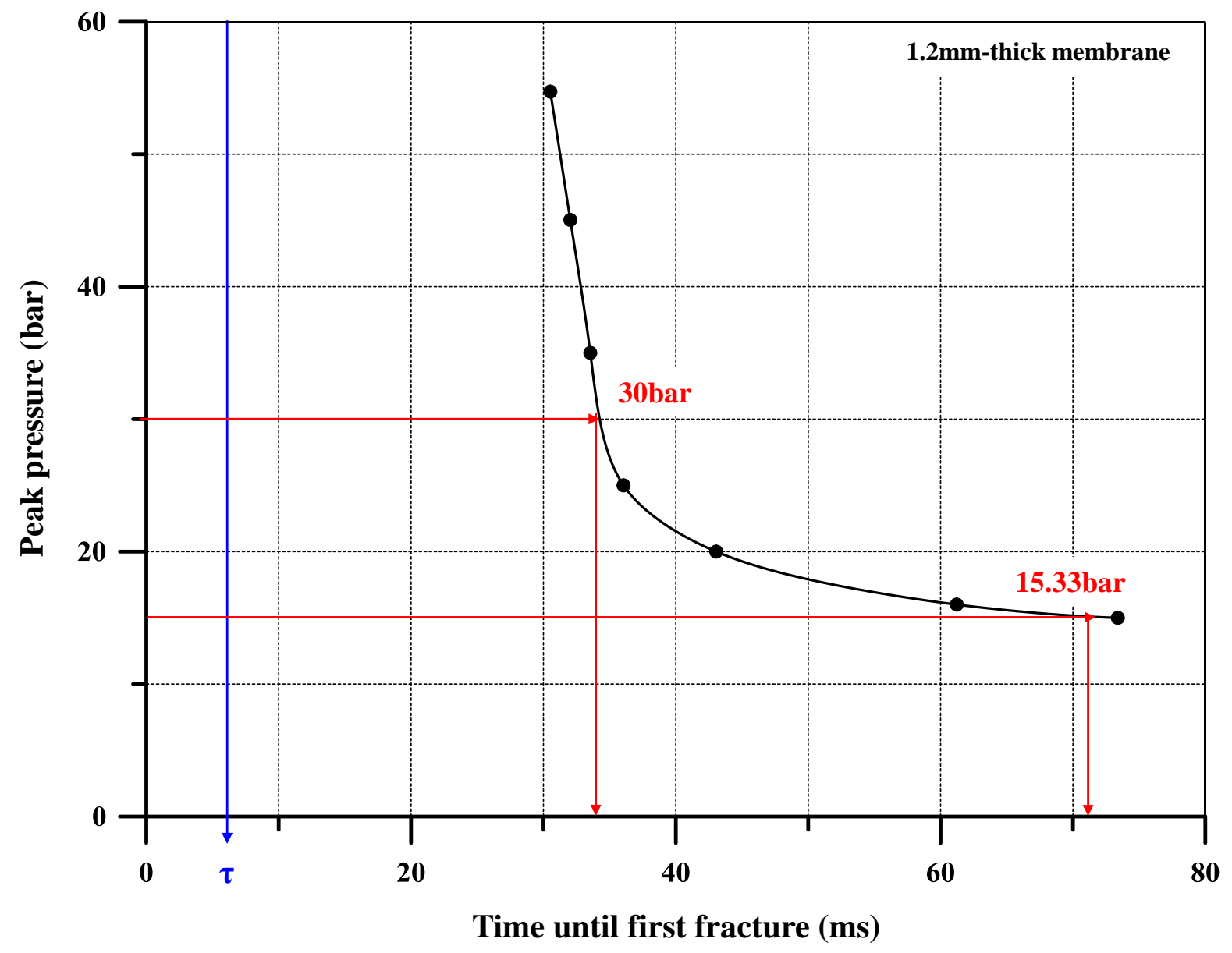

Figure 10. Peak pressure against the time until first fracture occurs. 


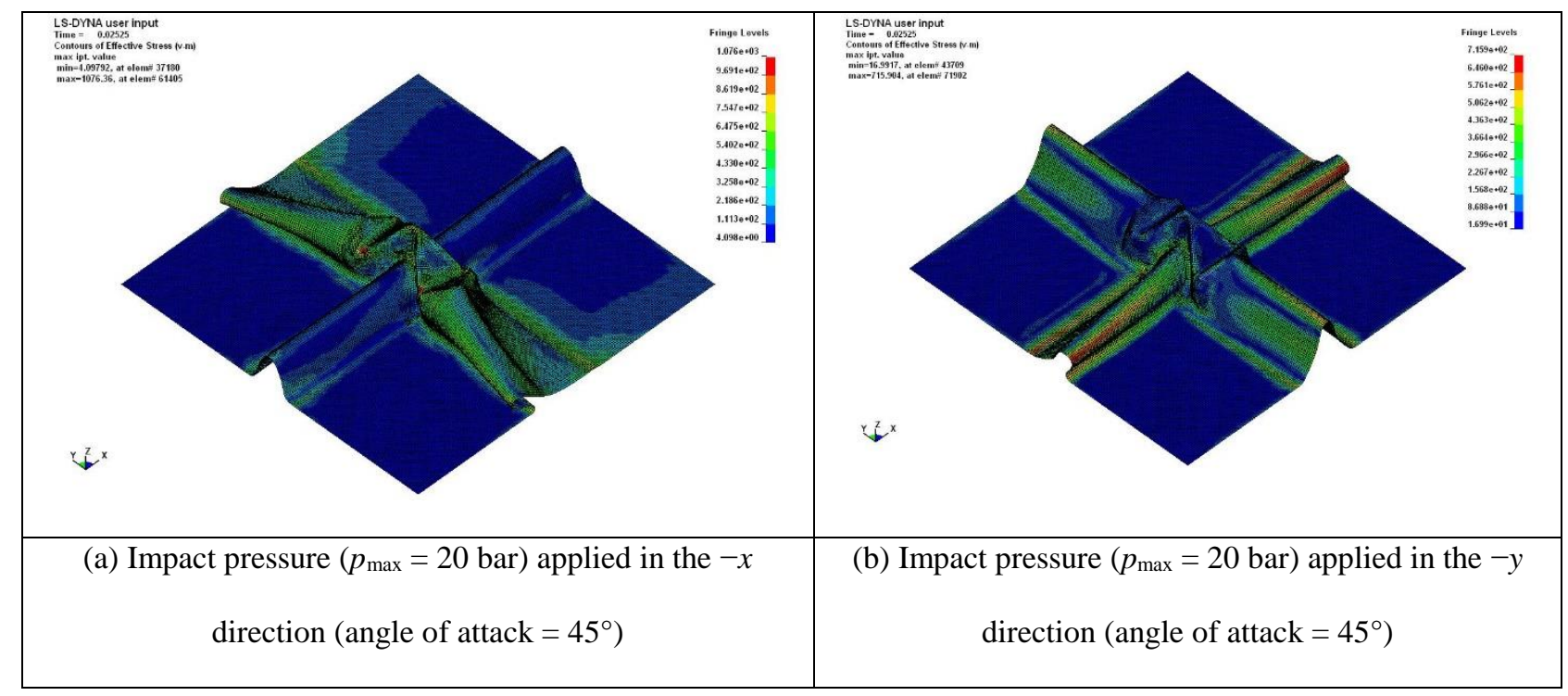

Figure 11. von Mises stress distributions for impact pressures applied in $x$ and $y$ directions.

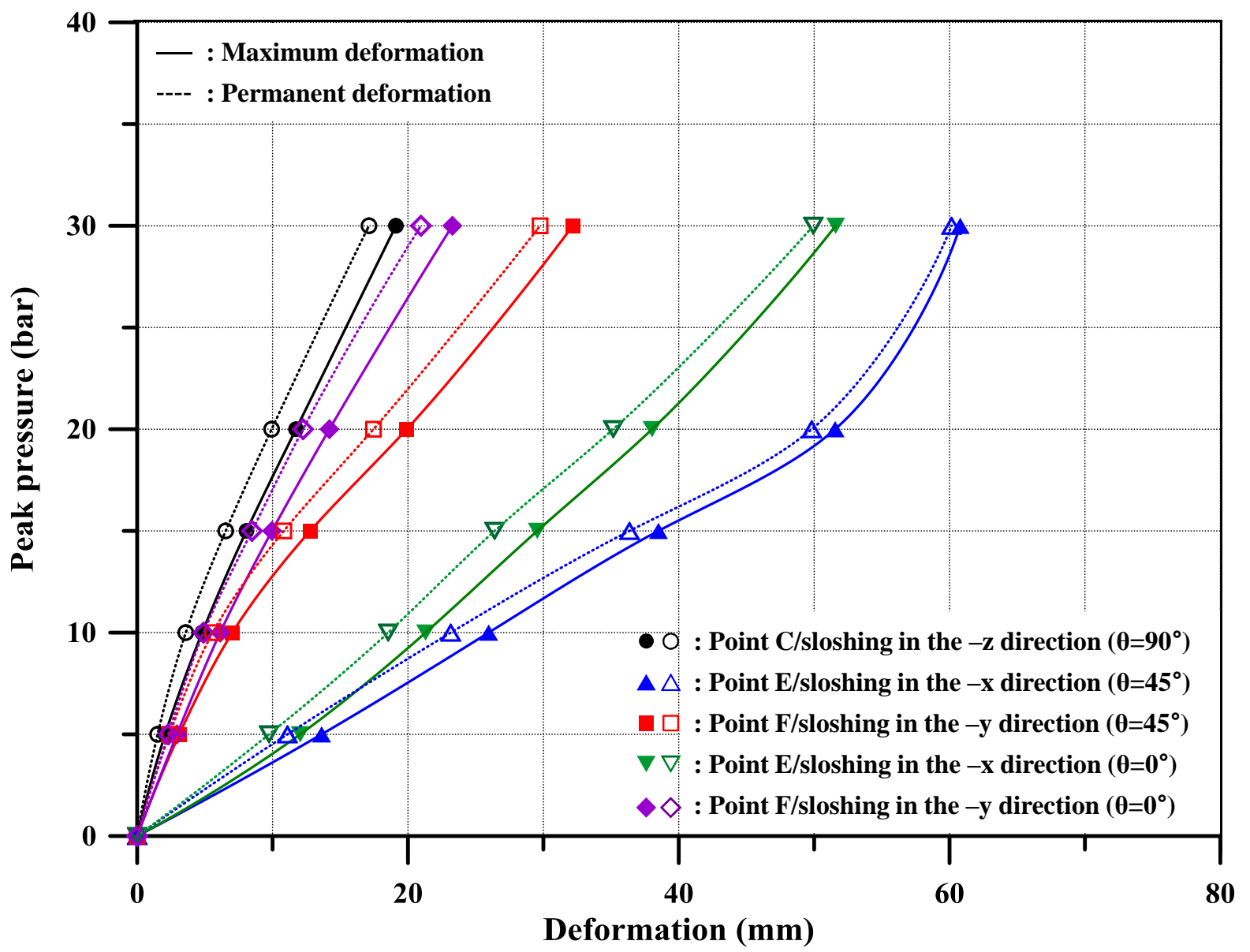


Figure 12. Comparisons between maximum and permanent deflection.

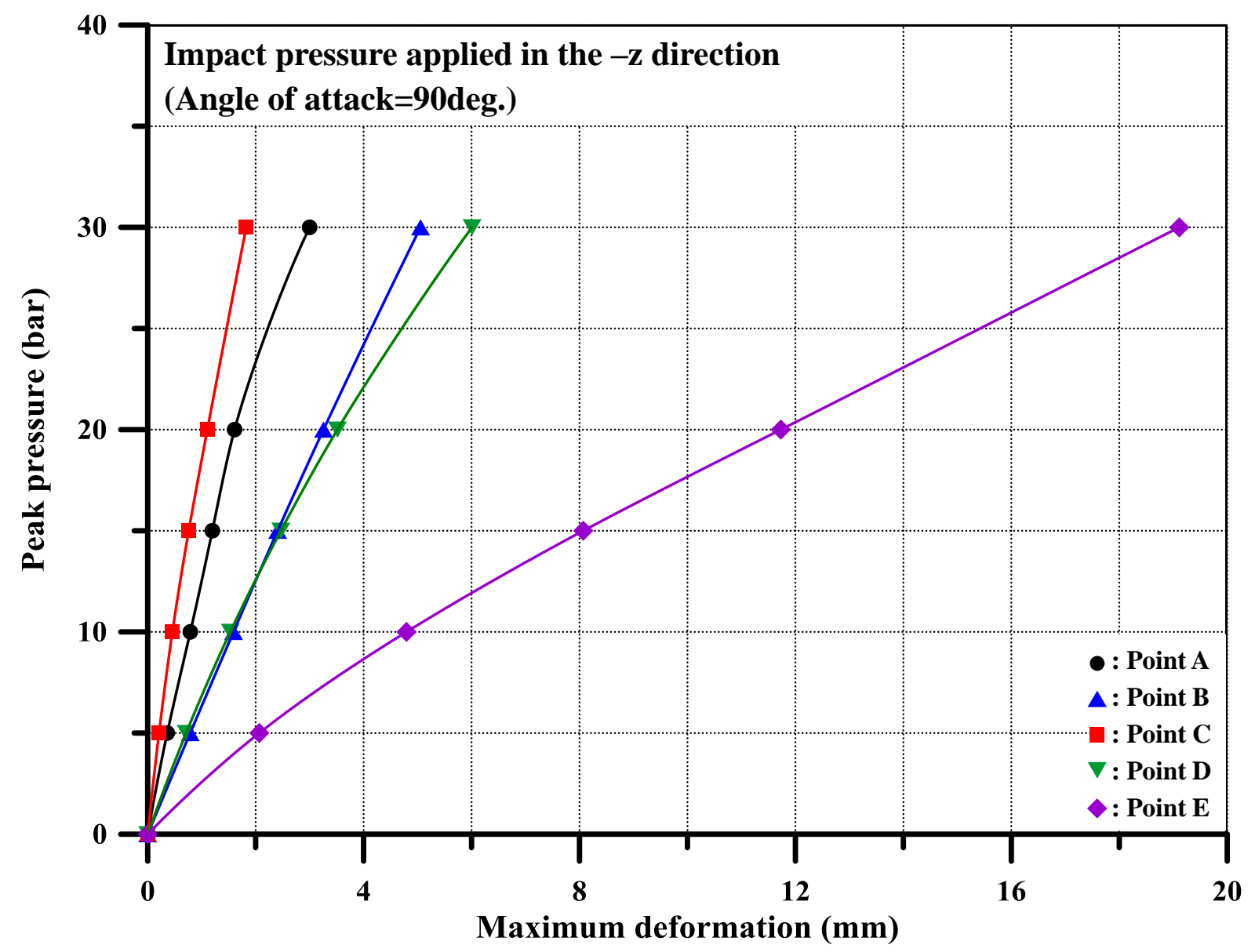

Figure 13 Peak pressure versus deformation of the corrugation at the angle of $\theta=90^{\circ}$ of sloshing pressure. 


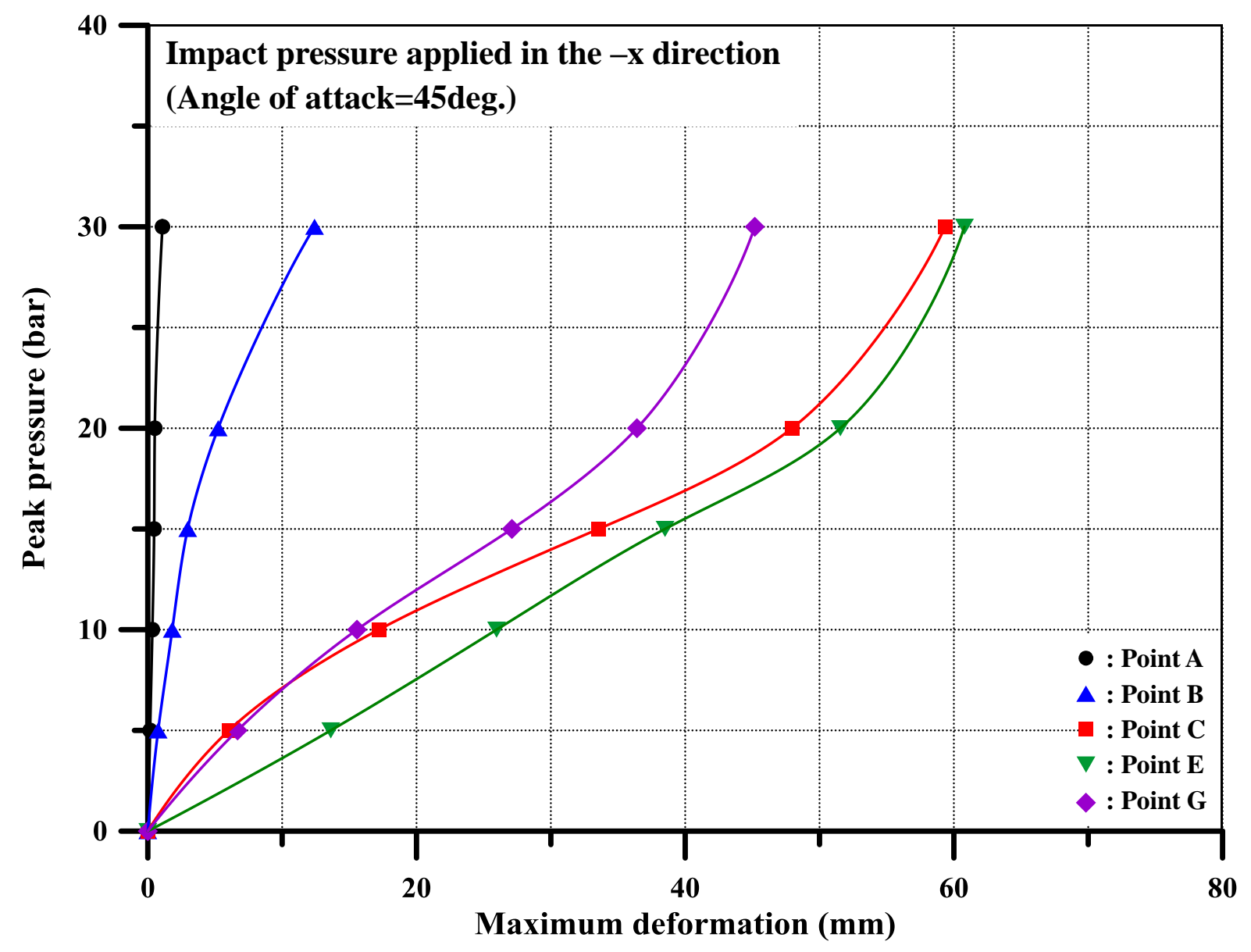

Figure 14. Peak pressure versus deformation of large corrugation; $\theta=45^{\circ}$ in the $-x$ direction. 


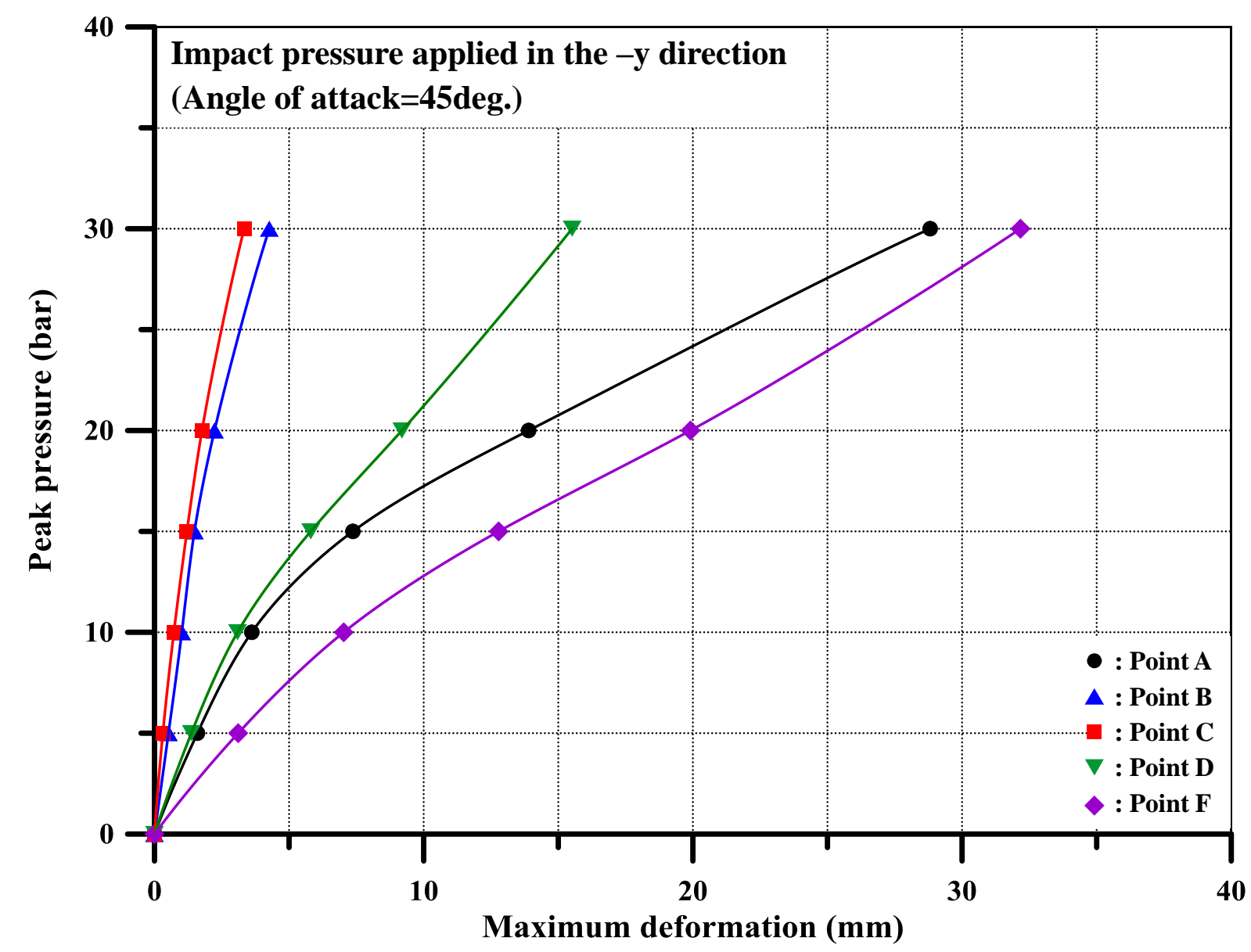

Figure 15. Peak pressure versus deformation of the small corrugation at the angle of attack; $\theta=$ $45^{\circ}$ in the $-y$ direction. 


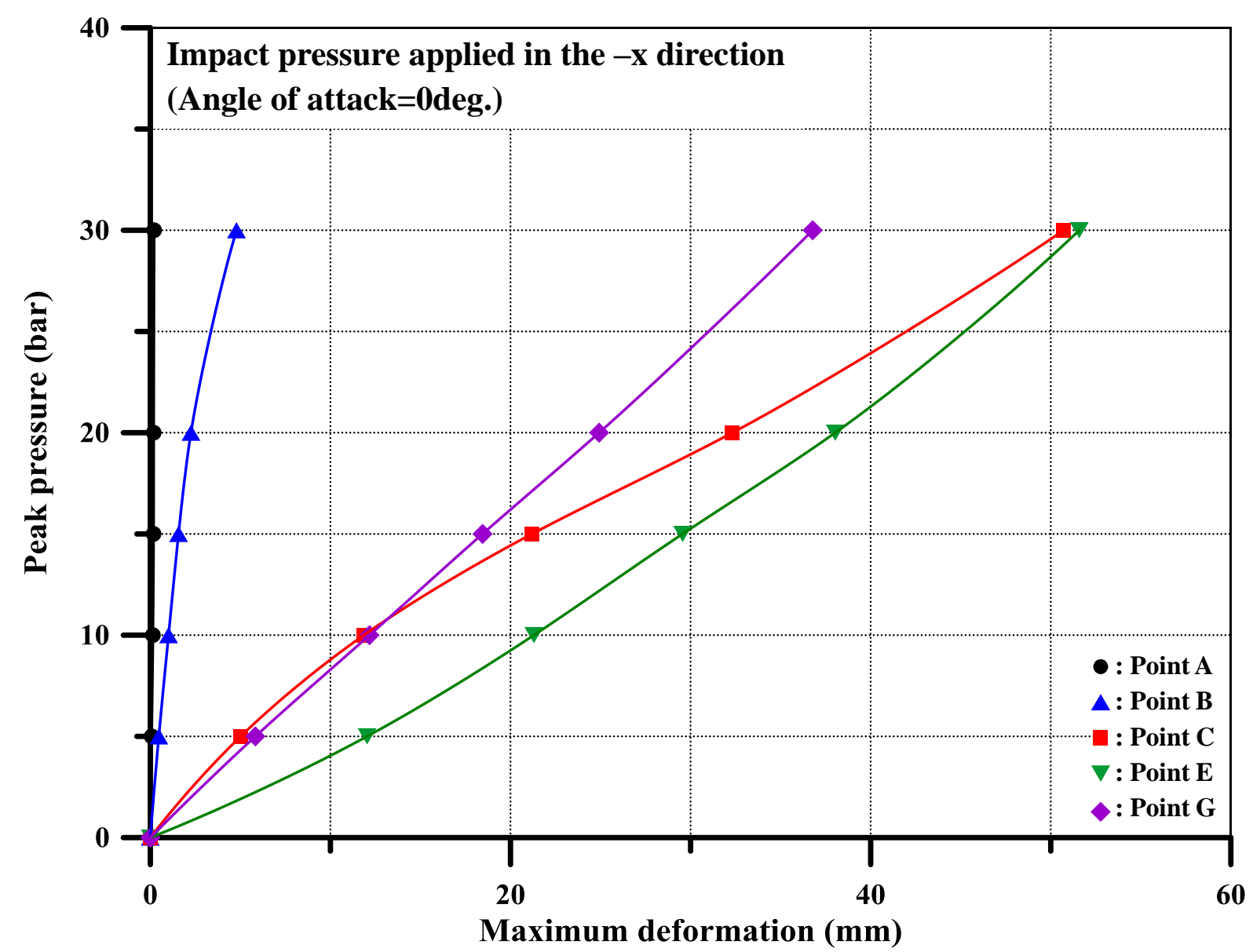

Figure 16. Peak pressure versus deformation of large corrugation at the angle of attack; $\theta=0^{\circ}$ in the $-x$ direction. 


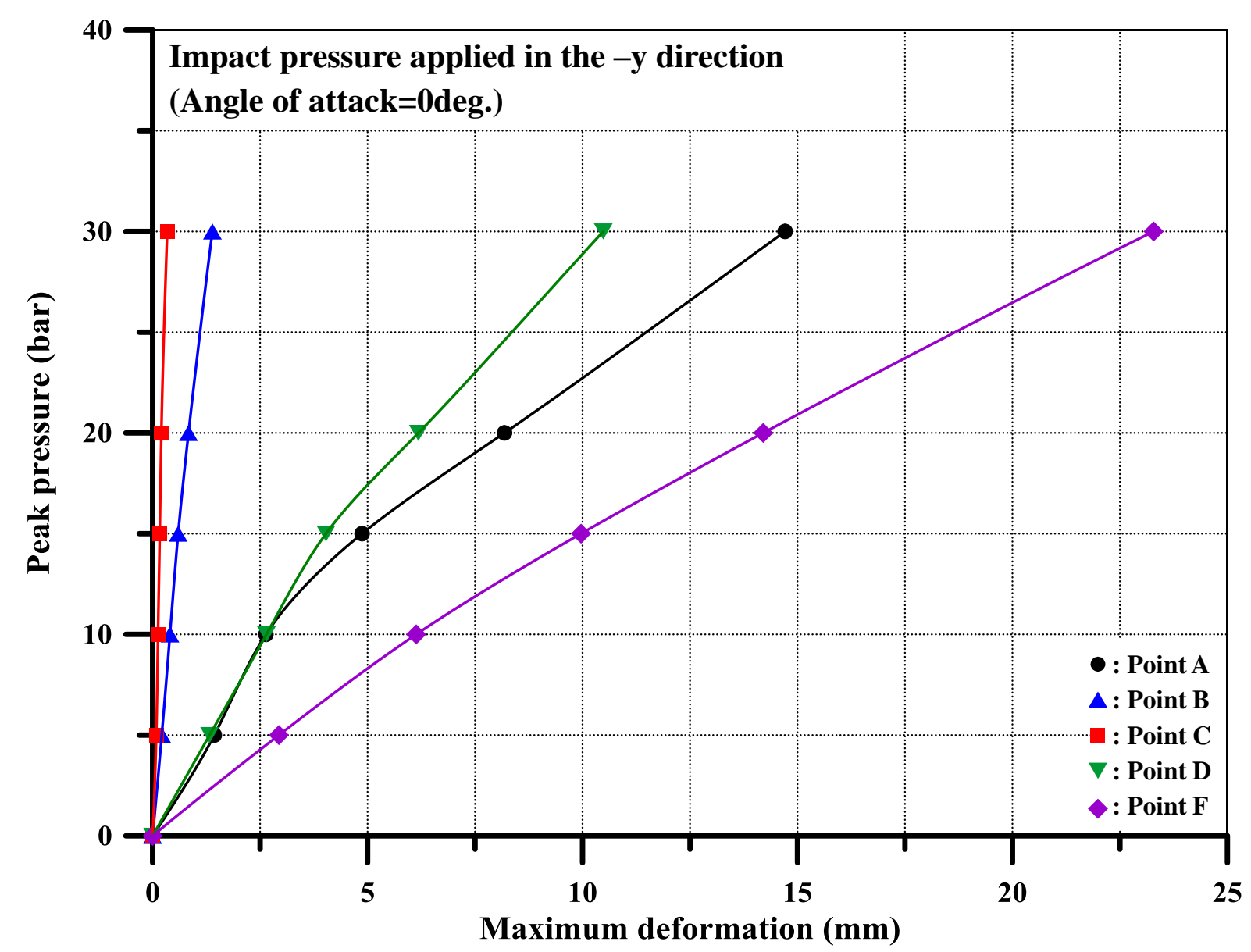

Figure 17. Peak pressure versus deformation of the small corrugation at the angle of attack; with $\theta=0^{\circ}$ in the $-y$ direction. 


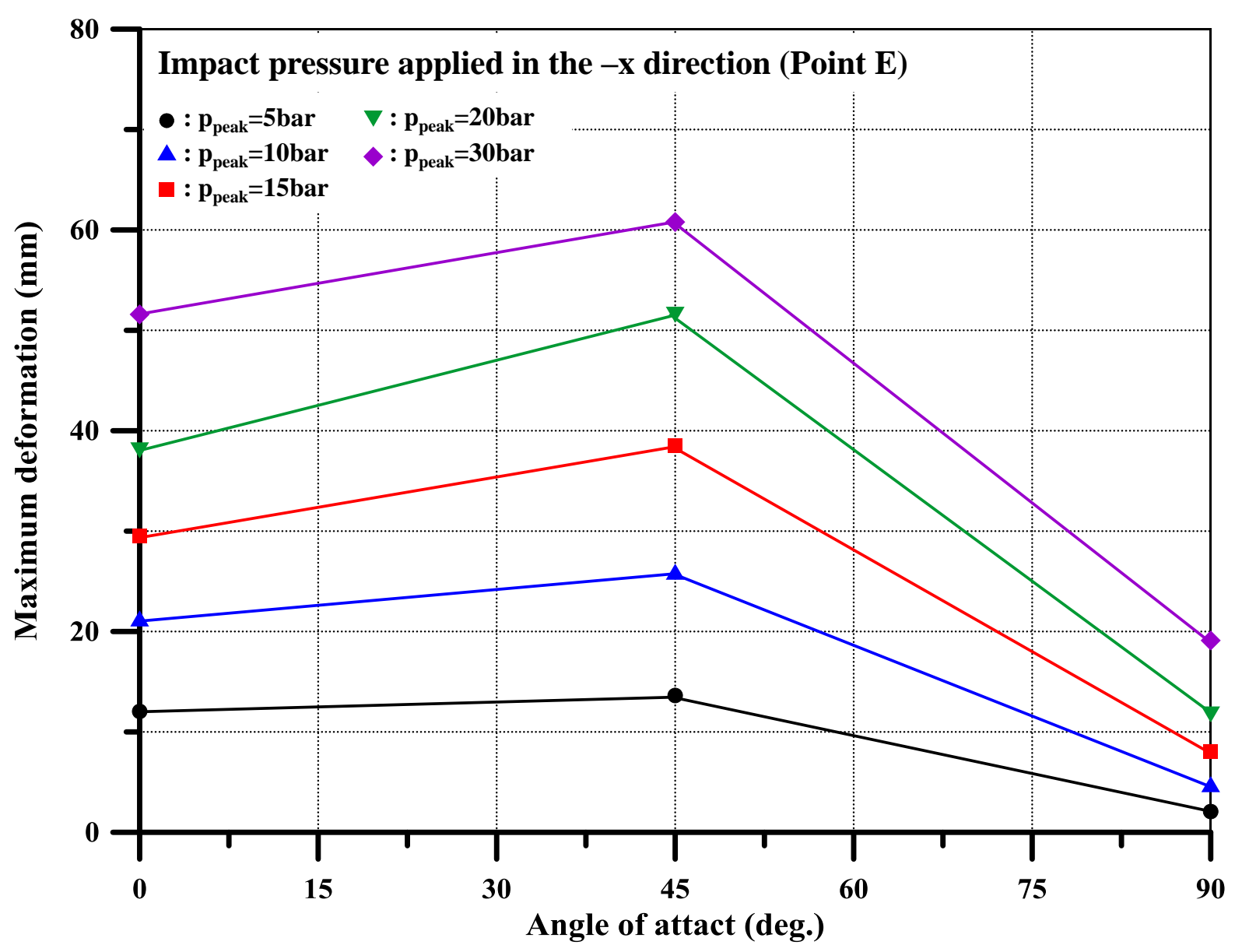

Figure 18. Effect of the angle of attack on the deformation of the corrugation at monitoring point E for impact pressure applied in the $-x$ direction. 


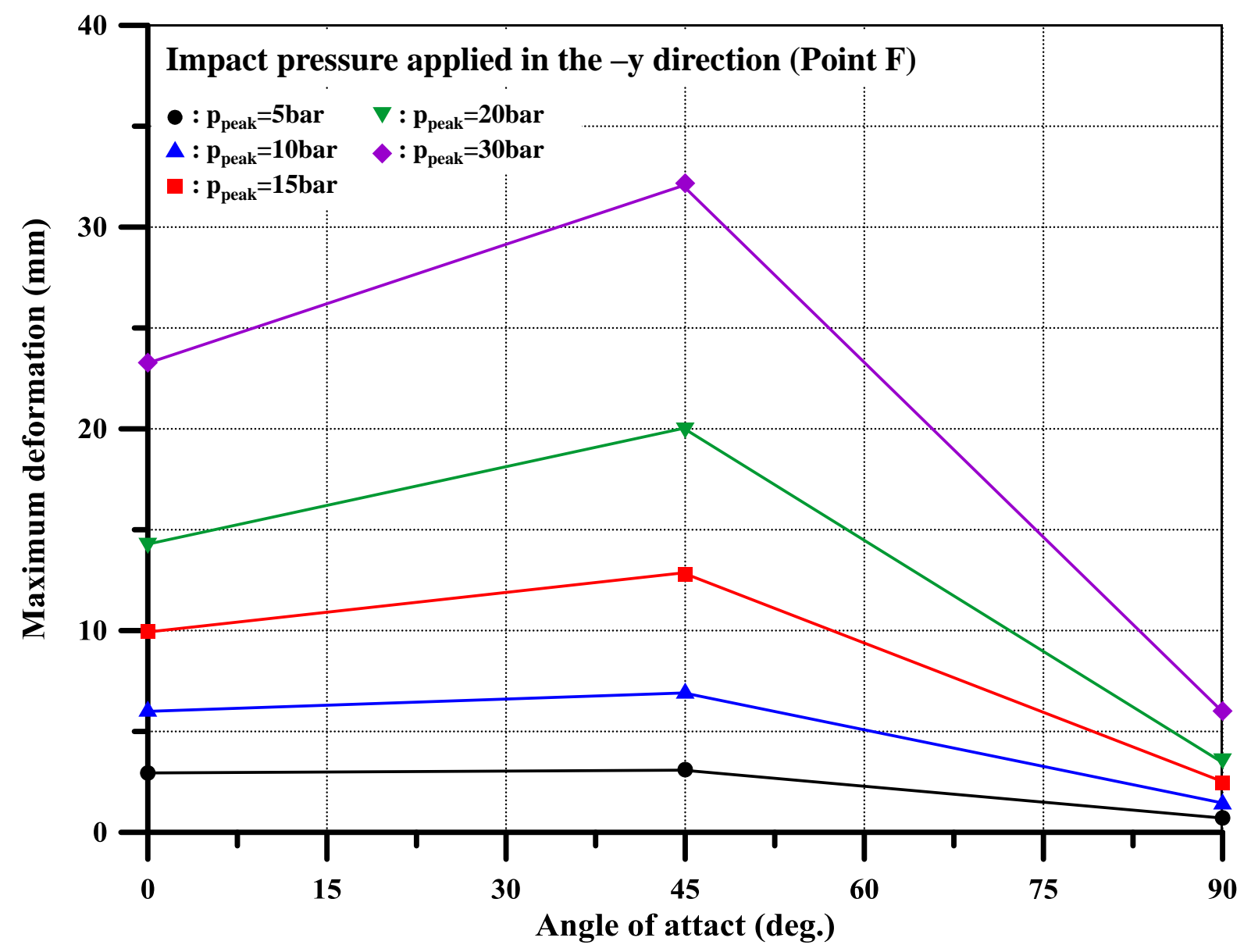

Figure 19. Effect of the angle of attack on the deformation of the corrugation at monitoring point F for impact pressure applied in the $-y$ direction. 
Table 1. Comparison of displacements and simulation times for different shell element formulations.

\begin{tabular}{|c|c|c|c|c|c|c|}
\hline \multirow{2}{*}{$\begin{array}{c}\text { ELFOR } \\
\text { M }\end{array}$} & \multicolumn{5}{|c|}{ Displacement in the $z$ direction $(\mathrm{mm})$} & \multirow{2}{*}{$\begin{array}{l}\text { Simulation time } \\
\text { (h:min:s) }\end{array}$} \\
\hline & $\mathrm{A}$ & B & $\mathrm{C}$ & $\mathrm{D}$ & $\mathrm{E}$ & \\
\hline 1 & -1.44 & -1.91 & -0.50 & -1.93 & -4.28 & $05: 49: 15$ \\
\hline 2 & -1.45 & -1.89 & $\begin{array}{c}-0.52 \\
6\end{array}$ & -1.91 & -4.24 & $05: 21: 37$ \\
\hline 6 & -1.45 & -1.88 & -0.50 & -1.90 & -4.17 & $14: 17: 3$ \\
\hline 16 & -1.44 & -1.88 & $\begin{array}{c}-0.50 \\
6\end{array}$ & -1.90 & -4.40 & $07: 36: 17$ \\
\hline
\end{tabular}

Table 2. Coefficients of the Cowper-Symonds constitutive equation for different steel types.

\begin{tabular}{|c|c|c|l|}
\hline Material & $C(1 / \mathrm{s})$ & $q$ & \multicolumn{1}{|c|}{ Reference } \\
\hline Mild steel & 40.4 & 5 & Cowper and Symonds (1957) \\
\hline High-tensile steel & 3,200 & 5 & Paik and Chung (1999) \\
\hline \multirow{2}{*}{$\begin{array}{c}\text { Stainless steel } \\
(304 \mathrm{~L})\end{array}$} & 100 & 10 & Forrestal and Sagartz (1978) \\
\cline { 2 - 4 } & 5,000 & 5.3 & Langdon and Schleyer (2005) \\
\cline { 2 - 4 } & 39,033 & 5.136 & Hsu and Jones (2004) \\
\cline { 2 - 4 } & 12,500 & 4.5 & Paik and Kim (2009) \\
\hline
\end{tabular}

Table 3. Summary of von Mises stresses for different loading patterns. 


\begin{tabular}{|c|c|c|c|c|c|}
\hline & \multicolumn{5}{|c|}{ von Mises stress (MPa) } \\
\hline $\begin{array}{c}\text { direction } \\
p_{\text {peak }} \text { (bar) }\end{array}$ & $-z$ & $-x$ with $\theta=0^{\circ}$ & $-x$ with $\theta=45^{\circ}$ & $-y$ with $\theta=0^{\circ}$ & $-y$ with $\theta=45^{\circ}$ \\
\hline 5 & 406.454 & 544.020 & 547.254 & 361.306 & 395.315 \\
\hline 10 & 480.380 & 629.283 & 750.437 & 470.134 & 496.317 \\
\hline 15 & 500.028 & 744.164 & 954.936 & 536.798 & 597.291 \\
\hline 20 & 713.744 & 851.562 & 1076.360 & 590.309 & 715.904 \\
\hline 30 & 738.710 & 1178.570 & 1267.900 & 685.860 & 953.179 \\
\hline
\end{tabular}

